\title{
THE CONCENTRATION OF SELECTED HEAVY METALS IN POPLAR WOOD BIOMASS AND LIQUID FRACTION OBTAINED AFTER HIGH TEMPERATURE PRETREATMENT
}

\author{
Donata Krutul, Jan Szadkowski, Andrzej Antczak, \\ Michae Drożdżek, Andrzej Radomski, Staniseaw Karpiński, \\ JANusZ ZaWADZKI \\ Warsaw University of Life Sciences \\ Poland \\ (Received May 2020)
}

\begin{abstract}
The concentration of selected heavy metals: chromium $(\mathrm{Cr})$, manganese $(\mathrm{Mn})$, iron ( $\mathrm{Fe})$, nickel $(\mathrm{Ni})$, copper $(\mathrm{Cu})$ and zinc $(\mathrm{Zn})$ in 5-year-old wood of Populus trichocarpa before and after steam explosion (SE) and liquid hot water (LHW) pretreatments was studied. The concentration of the above heavy metals in the liquid fraction obtained after pretreatments was also studied. The studied problem of heavy metals in lignocellulosic biomass is an interesting and important issue in the context of bioethanol production technology. An X-ray fluorescence spectrometer (XRF) was used to analyse the concentration of heavy metals. The change of concentration of the tested elements in wood biomass after pretreatment was small (except for iron). On the other hand, the average concentration of iron in wood biomass of a 5-year-old Populus trichocarpa, after SE and LHW with duration of the pretreatments 15 and $60 \mathrm{~min}$, increased about 24-fold to 28-fold, comparing to its average concentration in native wood. During the pretreatment process, wood biomass absorbed the iron that at high temperatures passed from the pretreatment equipment to the solution. The average concentration of the elements under research in liquid fraction obtained during SE and LHW of wood biomass with duration of the pretreatments 15 and 60 min was at a low level.
\end{abstract}

KEYWORDS: Populus trichocarpa, poplar, steam explosion, liquid hot water, liquid fraction, heavy metals.

\section{INTRODUCTION}

Nowadays biomass hydrolysis is preferably performed via the enzymatic process, although acidic hydrolysis is better known. Acidic hydrolysis causes a higher negative impact on the natural 
environment and that is why the application using enzymes has been focused on. Enzymatic hydrolysis is basically a well known process and has been used many times by different authors (Mansfield et al. 1999, Palonen et al. 2004, Martin et al. 2008, Kumar and Wyman 2009, Studer et al. 2011, Antczak et al. 2018, Antczak et al. 2019), but the high cost of the enzymes to be used make the process unprofitable. The content of possible enzymatic hydrolysis inhibitors in raw material is also a very important factor which should be taken in to account.

The technological process of biofuel production from wood biomass can be hindered by organic and inorganic inhibitors. Among organic substances, it is worth mentioning furan aldehydes created mostly as a result of decomposition and further transformations of hemicelluloses to furfural, 5-hydroxymethylfurfural, as well as soluble phenolic compounds appearing due to lignin degradation (Palmqvist and Hahn-Hägerdal 2000a, b, Klinke et al. 2002, Garcia-Aparicio et al. 2006, Alvira et al. 2010, Horn et al. 2011, Tomás-Pejó et al. 2011, Chandel et al. 2013, Jönsson et al. 2013).

Poplar is a known fast-growing species which can be used for biofuel production. It may be useful as a raw material further processed to biogas or liquid biofuels (Antczak et al. 2014, Antczak et al. 2018).

Inorganic inhibitors include some heavy metals which can accumulate in the trees depending on their growth environment, as well as in the wood during the process of its impregnation finish, as well as during pretreatment of lignocellulosic biomass during its preparation for biofuel production. The source of contamination with metals can be compounds and alloys used to manufacture the blades of industrial wood grinders, as well as reactors, in which the pretreatment processing takes place (Palmqvist and Hahn-Hägerdal 2000a,b). During pretreatment, high temperature and pressure can facilitate the transfer of metals from the machines into wood biomass. Metals can also pass to the liquid fraction created after pretreatment (Warzee et al. 1966). The salts of chromium, iron, nickel and copper are metal compounds considered to be inhibitors in wood biomass pretreatment processes and its fermentation (Warzee et al. 1966, Chandel et al. 2013). Moreover, some of metal ions may additionally bind to lignin, causing a change in the energy potential of the biomass leading to an increase of enzymatic hydrolysis efficiency (Liu and Zhu 2010, Akimkulova et al. 2016). The process of enzymatic hydrolysis of wood biomass leads to ions of such metals being combined with proteins, which causes their denaturation and deactivation, and as a consequence: lower efficiency of glucose production. In the available literature, there is scarce information on studies of heavy metals concentration released during pretreatment such as steam explosion and liquid hot water of poplar wood biomass.

The aim of this paper was to investigate the concentration of selected heavy metals in 5-year-old Populus trichocarpa wood biomass before and after SE and LHW pretreatments. The concentration of the above heavy metals in liquid fraction obtained after pretreatments was also studied.

\section{MATERIAL AND METHODS}

Material (mixed sapwood and hardwood) were obtained from the trunk of an about 5-year-old Populus trichocarpa. The high temperatures used in pretreatment processes of plant biomass cause the transmission of chemical compounds from the solid fraction to the liquid fraction used as reaction environment.

The measurement of heavy metal concentration in the wood was performed for such metals as $\mathrm{Cr}, \mathrm{Ni}, \mathrm{Cu}, \mathrm{Mn}, \mathrm{Zn}$ and $\mathrm{Fe}$, after the wood was burnt and converted to ashes. On the other hand, in the liquid fraction generated after pretreatment, the measurement was conducted directly. 
The heavy metal concentration was measured with an X-ray fluorescence spectrometer Spectro Midex M. The spectrometer was equipped with a $540 \times 600 \times 2500 \mathrm{~mm}$ chamber, with test bench positioning with the precision of $2.5 \mu \mathrm{m}$. Measurement points were set with the help of a system of two cameras controlled by the Spectrum X-labro software, permitting very precise location of the measurement points and the position of the sample in relation to the detector. Moreover, the device was equipped with an X-ray lamp cooled with air, containing a molybdenum anode. The maximum power was $30 \mathrm{~W}$, and the maximum voltage, $50 \mathrm{kV}$. The heavy metal concentration was measured for wood biomass of Populus trichocarpa before and after SE and LHW processes.

Wood biomass was converted into ashes in a muffle furnace, which took 6 hours at $600^{\circ} \mathrm{C}$. The increase at temperature from $20^{\circ} \mathrm{C}$ to $600^{\circ} \mathrm{C}$ lasted for additional 2.5 hours. Samples were converted to ashes in order to concentrate them (Harju et al. 1997).

Wood biomass was subjected to steam explosion in a stainless steel autoclave. According to the technical specification (Explo Solution company), the autoclave was made of 316Ti stainless steel (complaint with the PN-EN 10088-1) characterized by the following composition: C- max. $0.080 \%$, Mn- max. 2.00\%, Si- 0.75\%, P- 0.045\%, S- 0.030\%, Cr- $16.00 \div 18.00 \%$, Ni- $10 \div$ $14.00 \%$, Mo- $2.00 \div 3.20 \%$, Ti- max. $0.70 \%$, N- max. $0.10 \%$. The interchangeable elements of the apparatus, in accordance with the technical specification (Explo Solution company), are made of $\mathrm{CuZn} 33$ brass (complaint with the PN-EN 1652), composed of: $\mathrm{Cu}-66.0$ up to $68.0 \%, \mathrm{~Pb}$ max. 0.05\%, Al- max. 0.02\%, Fe- $\max$. 0.05\%, Ni- $\max .0 .3 \%$, Sn- $\max .0 .1 \%$ and $\mathrm{Zn}-31.5 \%$.

The wood biomass of a 5-year-old Populus trichocarpa was subjected to the processes of $\mathrm{SE}$ and LHW. The processes were done in a stainless-steel reactor with a total volume of $250 \mathrm{~cm}^{3}$. To each of pretreatment process about $20 \mathrm{~g}$ of size reduced (fraction between 0.43 and $1.02 \mathrm{~mm}$ ) wood was used. Before the pretreatment, the wood in the reactor was supplemented with distilled water to a volume of $250 \mathrm{~cm}^{3}$. The ratio of wood to distilled water was 1:12.5. The SE and LHW processes were conducted at temperatures of $160^{\circ} \mathrm{C}, 175^{\circ} \mathrm{C}$ and $190^{\circ} \mathrm{C}$, with duration of the pretreatments 15 and $60 \mathrm{~min}$. The concentration of selected metals in the liquid fraction obtained after pretreatments was tested in drops, whose volume amounted to about $0.3 \mathrm{~cm}^{3}$ of liquid. In addition, the concentration of heavy metals in distilled water, which was used during the pretreatment, was tested. For each processing temperature and pretreatment kind (SE and LHW) at least three drops of the same volume were tested, and one point of measurement was set in each of them. The test made use of a $2 \times 2 \mathrm{~mm}$ shutter and time of exposure of $300 \mathrm{sec}$.

\section{RESULTS AND DISCUSSION}

The results of the concentration of selected metals in native wood (biomass before the pretreatments) of a 5-year-old Populus trichocarpa, in wood after high temperature pretreatments with different residential times (15 and $60 \mathrm{~min}$ ), in distilled water and in liquid fraction are presented in Figs. 1-6. On the basis of the data presented in Fig. 1, we can conclude that the chromium concentration in wood biomass subjected to steam explosion, independently of the temperature and time of pretreatment, doubled or tripled, comparing with the concentration of this metal in native wood and in distilled water. The average concentration of chromium in liquid fraction oscillated between 26.0-29.0 ppm, independently of the steam explosion temperature and heating temperature residential time.

The data provided by Zielenkiewicz et al. (2016) indicate that the concentration of chromium in a native wood of 2.5-year-old Populus trichocarpa amounted to $11 \mathrm{ppm}$, which is consistent with the data obtained for a native wood of 5-year-old Populus trichocarpa (10.0 ppm). The average 
concentration of chromium in the wood biomass of the 5-year-old Populus trichocarpa after the LHW process with residential times of 15 and $60 \mathrm{~min}$ it was similar to its concentration in wood biomass after steam explosion, and fell in the range between $17.0 \mathrm{ppm}$ and $41.0 \mathrm{ppm}$ (Fig. 1).

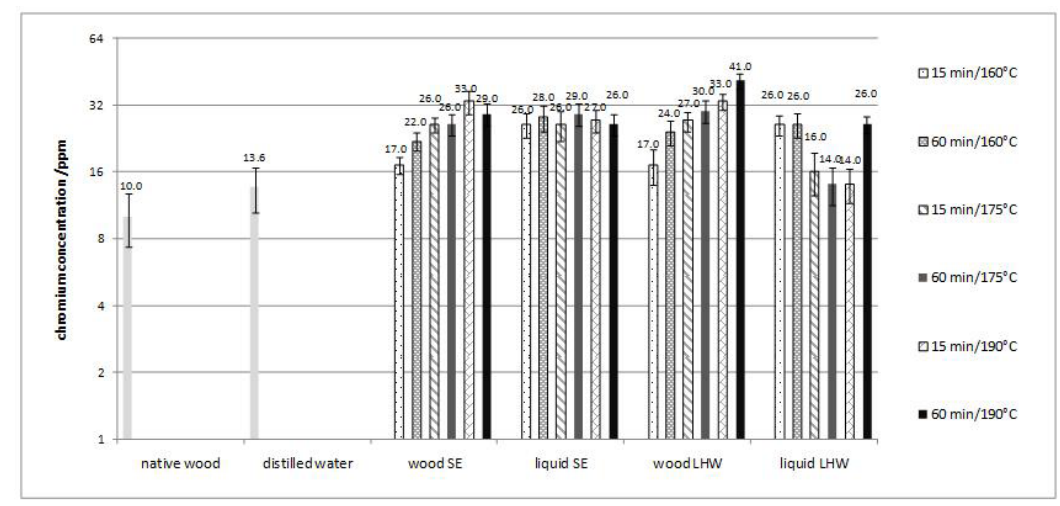

Fig. 1: Chromium concentration in native wood of a 5-year-old Populus trichocarpa, in wood after high temperature pretreatments (SE and LHW) with different residential times (15 and $60 \mathrm{~min}$ ), in distilled water and in liquid fraction obtained after above pretreatments.

In the wood biomass of a 2.5 year-old Populus trichocarpa subjected to steam explosion at the temperatures of $160^{\circ} \mathrm{C}$ and $190^{\circ} \mathrm{C}$, the concentration of chromium was $17 \mathrm{ppm}$ and $32 \mathrm{ppm}$, respectively. In the wood biomass of a 5 year-old Populus trichocarpa subjected to steam explosion at the temperatures of $160^{\circ} \mathrm{C}, 175^{\circ} \mathrm{C}$ and $190^{\circ} \mathrm{C}$, the average concentration of chromium was from $17.0 \mathrm{ppm}$ to $33.0 \mathrm{ppm}$, in both heating times: 15 and $60 \mathrm{~min}$. To sum up, it can be concluded that both native wood and wood biomass after steam explosion have a low concentration of chromium. Similarly, in the liquid fraction obtained after SE and LHW, the average concentration of this element fell in the range between $14.0 \mathrm{ppm}$ and $29.0 \mathrm{ppm}$ (Fig. 1).

On the basis of data presented in Fig. 2, it can be concluded that the concentration of nickel in the wood of the 5-year-old Populus trichocarpa and wood biomass after high temperature treatment was similar to the chromium concentration (Fig. 1). In wood biomass after steam explosion at the temperatures of $175^{\circ} \mathrm{C}$ and $190^{\circ} \mathrm{C}$, with residential times of 15 and $60 \mathrm{~min}$, the average concentration of nickel was two and three times higher than its average concentration in native wood or in distilled water, and fell in the range between $34.0 \mathrm{ppm}$ and $51.0 \mathrm{ppm}$. According to Zielenkiewicz et al. (2016), in the wood biomass of a 2.5 year-old Populus trichocarpa subjected to steam explosion at the temperatures of $160^{\circ} \mathrm{C}$ and $190^{\circ} \mathrm{C}$, with residential times of 15 and $60 \mathrm{~min}$, the concentration of nickel amounted to $16 \mathrm{ppm}$ and $40 \mathrm{ppm}$, respectively. For the liquid fraction obtained after steam explosion treatment of the wood biomass of a 5-year-old Populus trichocarpa at the temperatures of $160^{\circ} \mathrm{C}, 175^{\circ} \mathrm{C}$ and $190^{\circ} \mathrm{C}$, with residential times of 15 and $60 \mathrm{~min}$, the average concentration of nickel fell in the range between $38.0 \mathrm{ppm}$ and $41.0 \mathrm{ppm}$ (Fig. 2). Similarly to the concentration of chromium and nickel, the average concentration of copper in the native wood of a 5-year-old Populus trichocarpa was low and amounted to $14.0 \mathrm{ppm}$ (Fig. 3). 


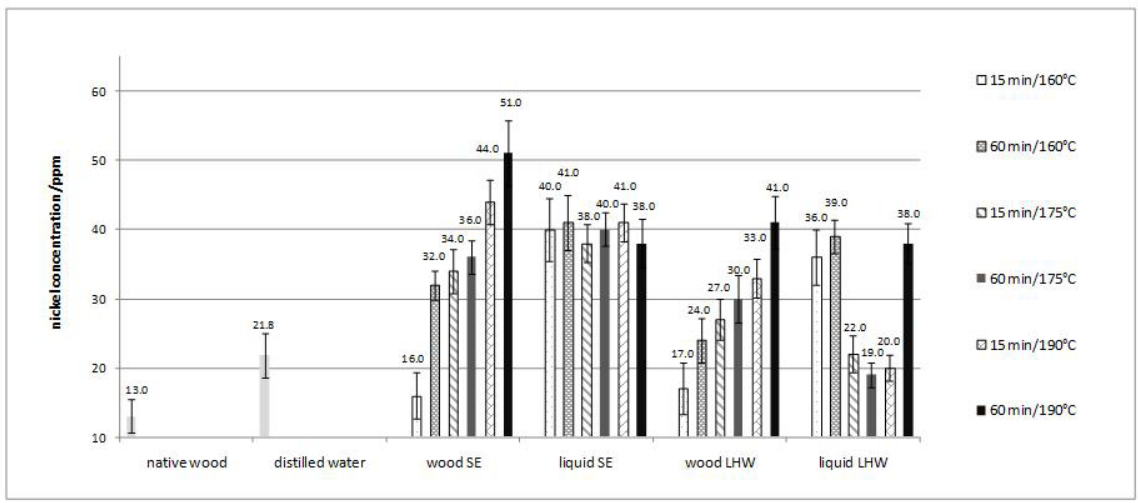

Fig. 2: Nickel concentration in native wood of a 5-year-old Populus trichocarpa, in wood after high temperature pretreatments (SE and LHW) with different residential times (15 and $60 \mathrm{~min}$ ), in distilled water and in liquid fraction obtained after above pretreatments.

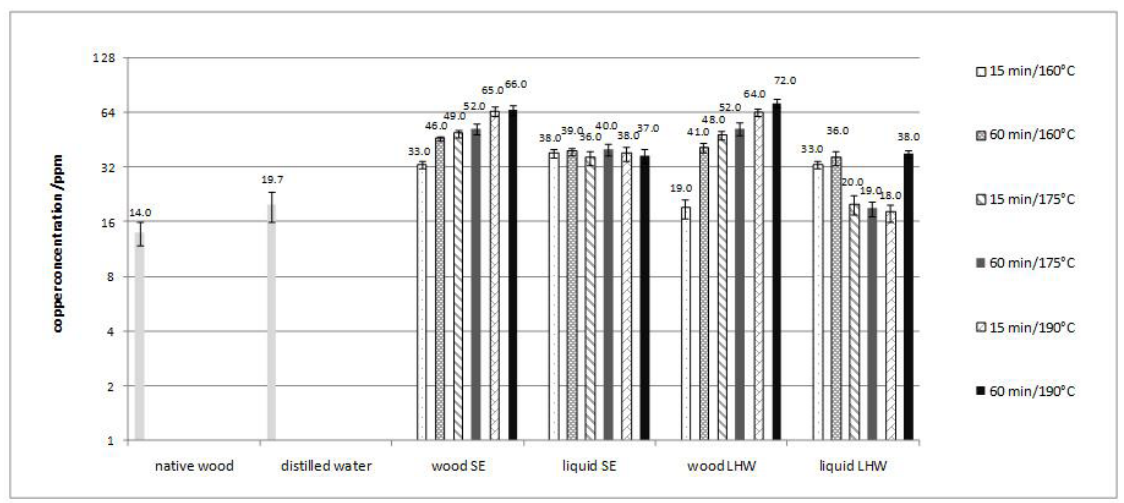

Fig. 3: Copper concentration in native wood of a 5-year-old Populus trichocarpa, in wood after high temperature pretreatments (SE and LHW) with different residential times (15 and $60 \mathrm{~min}$ ), in distilled water and in liquid fraction obtained after above pretreatments.

Also according to Zielenkiewicz et al. (2016), the concentration of copper in the wood of a 2.5-year-old Populus trichocarpa amounted to $12 \mathrm{ppm}$ and its concentration increased 6-fold in the biomass after steam explosion treatment at $130^{\circ} \mathrm{C}, 3$-fold after the treatment at $160^{\circ} \mathrm{C}$, and 5 -fold after the treatment at $190^{\circ} \mathrm{C}$. On the basis of data presented in Fig. 3, we can see that the copper average concentration in wood biomass subjected to pretreatment with SE and LHW, with residential times of 15 and $60 \mathrm{~min}$, at the temperature of $190^{\circ} \mathrm{C}$ increased 4- and 5-fold comparing to its average concentration in native wood and increased 3-fold comparing to its average concentration in distilled water. The average concentration of copper in the liquid fraction changed irregularly together with the increase of process temperature and residential time during which the heating temperature was maintained.

Fig. 4 presents data concerning the concentration of manganese in the native wood of a 5-year-old Populus trichocarpa, in biomass after SE and LHW processes, as well as in distilled water and in the liquid fraction. The native wood of the 5-year-old Populus trichocarpa had 
a manganese average concentration of $118.0 \mathrm{ppm}$, which was similar to its concentration in the wood of a 2.5-year-old Populus trichocarpa, amounting to $120 \mathrm{ppm}$ (Zielenkiewicz et al. 2016). The average concentration of manganese in wood biomass after pretreatment with steam explosion, independently of the temperature and the residential time, did not change, while wood biomass after LHW contained about 10\% more of manganese comparing to its average concentration in native wood. In the liquid fraction obtained after pretreatment processes of wood biomass and in distilled water, the manganese average concentration was low and fell in the range between 12.0 ppm and 31.0 ppm (Fig. 4).

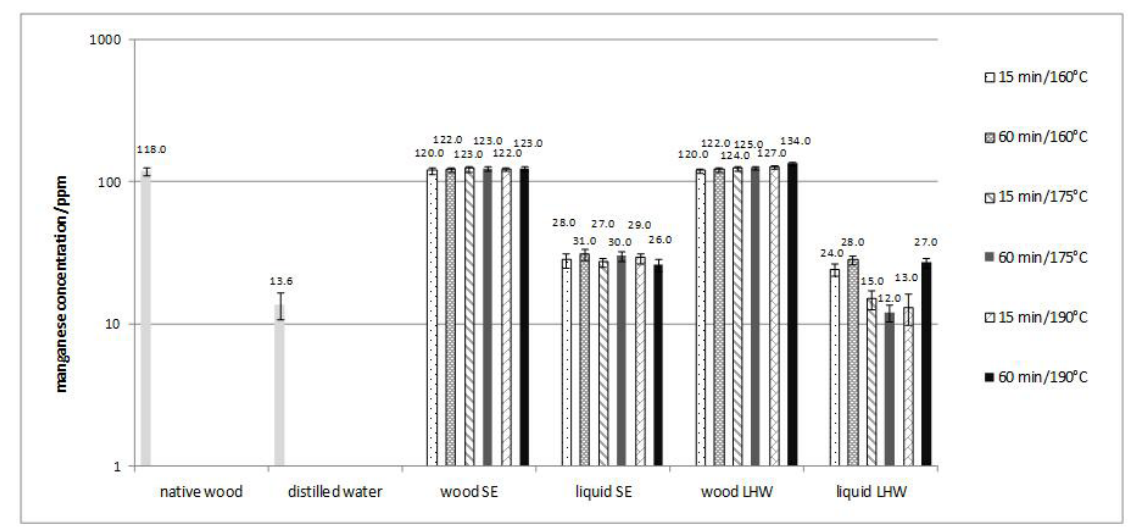

Fig. 4: Manganase concentration in native wood of a 5-year-old Populus trichocarpa, in wood after high temperature pretreatments (SE and LHW) with different residential times (15 and $60 \mathrm{~min}$ ), in distilled water and in liquid fraction obtained after above pretreatments.

The average concentration of zinc in the native wood of a 5-year-old Populus trichocarpa amounted to $155.0 \mathrm{ppm}$ (Fig. 5) and was similar to its concentration in a 2.5-year-old Populus trichocarpa, where it amounted to $160 \mathrm{ppm}$ (Zielenkiewicz et al. 2016). The concentration of zinc in wood biomass after SE and LHW processes increased together with the increase in process temperature and residential time, from about $10 \%$ to about $30 \%$.

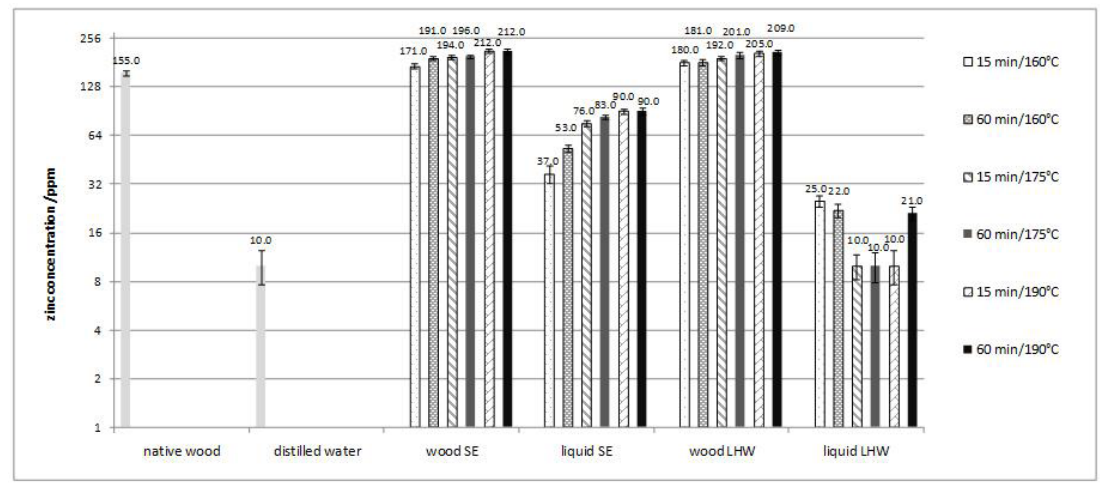

Fig. 5: Zinc concentration in native wood of a 5-year-old Populus trichocarpa, in wood after high temperature pretreatments (SE and LHW) with different residential times (15 and 60 min), in distilled water and in liquid fraction obtained after above pretreatments. 
According to Zielenkiewicz et al. (2016), the wood biomass of a 2.5 year-old Populus trichocarpa subjected to steam explosion at the temperature of $130^{\circ} \mathrm{C}$, with residential time of $15 \mathrm{~min}$, the concentration of zinc increased two-fold comparing to its concentration in native wood; while after the process at $160^{\circ} \mathrm{C}$ it did not change; and it increased by $20 \%$ after the steam explosion process at $190^{\circ} \mathrm{C}$. On the other hand, the concentration of zinc in the liquid fraction, generated as a result of pretreatment of wood biomass of a 5-year-old Populus trichocarpa both with SE and LHW, changed irregularly together with the increase in process temperatures and residential time during which the heating temperature was maintained.

On the basis of data presented in Fig. 6, we can conclude that the average concentration of iron in the wood of a 5-year-old Populus trichocarpa was low and amounted to $54.0 \mathrm{ppm}$. The iron average concentration in wood biomass after pretreatment processes ( $\mathrm{SE}$ and LHW) at the temperatures of $160^{\circ} \mathrm{C}, 175^{\circ} \mathrm{C}$ and $190^{\circ} \mathrm{C}$, with residential times of 15 and 60 minutes, grew from about 24 to 28 times, comparing to the iron average concentration in native wood. On the other hand, the average concentration of iron in the liquid fraction, generated as a result of pretreatment of wood biomass of a 5-year-old Populus trichocarpa both with SE and LHW, was low, as in distilled water, between $16.0 \mathrm{ppm}$ and $40.0 \mathrm{ppm}$. On the basis of the presented data, it can be concluded that during the SE and LHW pretreatment processes, wood biomass absorbed the iron that passed from the pretreatment equipment to the solution due to high temperatures. The data obtained are in line with the findings of Zielenkiewicz et al. (2016), suggesting that the wood biomass of a 2.5 year-old Populus trichocarpa subjected to steam explosion at the temperatures of $130^{\circ} \mathrm{C}, 160^{\circ} \mathrm{C}$ and $190^{\circ} \mathrm{C}$, without maintaining the heating temperature, contained a 43-times and 24-times higher iron concentration than the native wood.

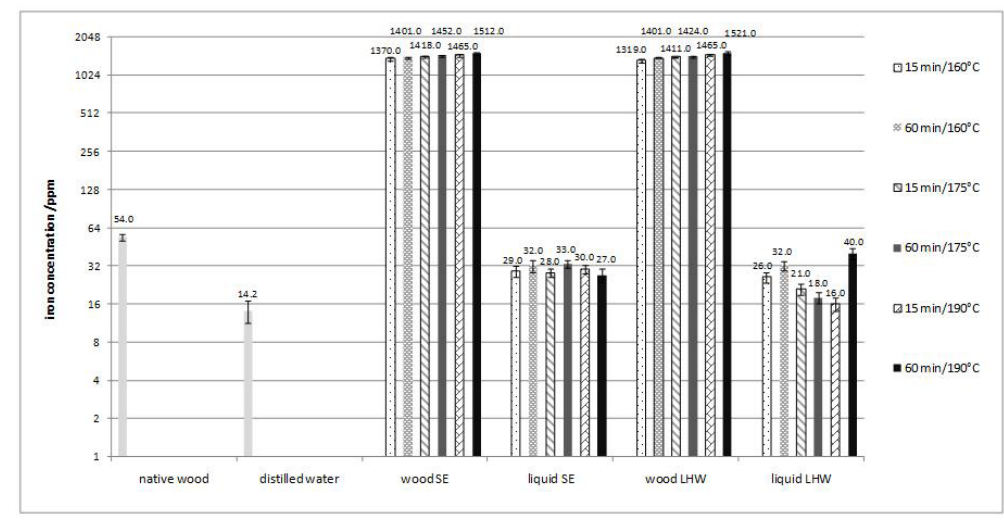

Fig. 6: Iron concentration in native wood of a 5-year-old Populus trichocarpa, in wood after high temperature pretreatments (SE and LHW) with different residential times (15 and $60 \mathrm{~min}$ ), in distilled water and in liquid fraction obtained after above pretreatments.

According to Roberge (1999), an increase in the content of metallic elements in wood biomass is caused by the corrosion process of the equipment used for pretreatment by high temperature hydrolysis and steam explosion and the contact of steel with substances released from wood biomass during these processes. The raw lignocellulosic biomass is prone to absorb heavy metals (Kord and Kord 2011).

Out of all the tested elements that can inhibit the bioethanol production process (chromium, nickel, copper and iron), the biggest variations happened in case of the concentration of iron 
in wood biomass, both after SE and LHW, independently of the process temperature and its residential time.

On the other hand, the average concentration of iron in the liquid fraction generated during the SE and LHW pretreatment processes of a 5-year-old Populus trichocarpa, with residential times of 15 and $60 \mathrm{~min}$, was low and fell in the range between $16.0 \mathrm{ppm}$ and $40.0 \mathrm{ppm}$.

\section{CONCLUSIONS}

The average concentration of all the tested elements that can inhibit the bioethanol production process (chromium, nickel, copper and iron) was quite low in native wood and ranged between $10.0 \mathrm{ppm}$ and $54.0 \mathrm{ppm}$. The average concentration of manganese and zinc in the native wood was higher, at the level of $118.0 \mathrm{ppm}$ and $155.0 \mathrm{ppm}$, respectively.

The concentration of iron in wood biomass of the 5-year-old Populus trichocarpa after pretreatment processes of SE and $\mathrm{LHW}$ at the temperatures of $160^{\circ} \mathrm{C}, 175^{\circ} \mathrm{C}$ and $190^{\circ} \mathrm{C}$, with residential times of 15 and $60 \mathrm{~min}$, increased from about 24 to 28 times, comparing to its average concentration in native wood. This means that during the pretreatment process, wood biomass absorbed iron that passed from the pretreatment equipment to the solution due to high process temperatures. The iron is an element considered to be a potential inhibitor in bioethanol production technology. The average concentrations of the tested elements: chromium, nickel, copper, zinc, manganese and iron, in the liquid fraction obtained during the pretreatment of wood biomass of a 5-year-old Populus trichocarpa in SE and LHW processes, with residential times of 15 and $60 \mathrm{~min}$, were low and fell in the range between $10.0 \mathrm{ppm}$ and $90.0 \mathrm{ppm}$.

\section{ACKNOWLEDGMENTS}

This work was financed by a research project from the National Centre for Research and Development, which was "Intelligent systems for breeding and cultivation of wheat, maize, and poplar for optimized biomass production, biofuels, and modified wood" (BIOSTRATEG2/298241/10/NCBR/2016). Poplar material used in presented work was obtained in Welcome 2008/1 project of the Foundation for Polish Science given to Prof. Stanisław Karpiński.

\section{REFERENCES}

1. Akimkulova, A., Zhou, Y., Zhao, X., Liu, D., 2016: Improving the enzymatic hydrolysis of dilute acid pretreated wheat straw by metal ion blocking of non-productive cellulase adsorption on lignin. Bioresource Technology 208: 110-116.

2. Alvira, P., Tomás-Pejó, E., Ballesteros, M., Negro, M.J., 2010: Pretreatment technologies for an efficient bioethanol production process based on enzymatic hydrolysis: A review. Bioresource Technology 101(13): 4851-4861.

3. Antczak, A., Marchwicka, M., Szadkowski, J., Drożdżek, M., Gawron, J., Radomski, A., Zawadzki, J., 2018: Sugars yield obtained after acid and enzymatic hydrolysis of fastgrowing poplar wood species. BioResources 13(4): 8629-8645.

4. Antczak, A., Spyszewska, N., Michałuszko, A., Kłosińska, T., Archanowicz, E., 2014: Acid hydrolysis of poplar wood (Populus sp.). Przemysł Chemiczny 93(8): 1428-1431. 
5. Antczak, A., Świerkosz, R., Szeniawski, M., Marchwicka, M., Akus-Szylberg, F., Przybysz, P., Zawadzki, J., 2019: The comparison of acid and enzymatic hydrolysis of pulp obtained from poplar wood (Populus sp.) by the Kraft method. Drewno 62(203): 53-66.

6. Chandel, A.K., Silvério da Silva, S., Singh, O.V., 2013: Detoxification of lignocellulose hydrolysate: biochemical and metabolic engineering toward white biotechnology. Bioenergy Research 6(1): 388-401.

7. Garcia-Aparicio, M.P., Ballesteros, J., Gonzalez, A., 2006: Effect of inhibitors released during steam explosion pretreatment of barley straw on enzymatic hydrolysis. Applied Microbiology and Biotechnology 129(1-3): 278-288.

8. Harju, L., Lill, J.O., Saarela, K.E., Heselius, S.J., Hernberg, F.J., Lindroos, A., 1997: Analysis of trace elements in trunk wood by thick-target PIXE using dry ashing for preconcentration. Fresenius Journal of Analytical Chemistry 358(4): 523-528.

9. Horn, S.J., Nguyen, Q.D., Westereng, B., Nilsen, P.J., Eijsink, N.G.H., 2011: Screening of steam explosion conditions for glucose production from non-impregnated wheat straw. Biomass and Bioenergy 35(12): 4879-4886.

10. Jönsson, L.J., Alrikssonn, B., Nivebrannt, N.O., 2013: Bioconversion of lignocellulose: inhibitors and detoxification. Biotechnology for Biofuels 6(1): 16-25.

11. Klinke, H.B., Ahring, B.K., Schmidt, A.S., Thomsen, A.B., 2002: Characterization of degradation products from alkaline wet oxidation of wheat straw. Bioresource Technology 82(1): 15-26.

12. Kord, B., Kord, B., 2011: Heavy metal levels in pine (Pinus eldarica Medw.) tree barks as indicators of atmospheric pollution. BioResources 6(2): 927-935.

13. Kumar, R., Wyman, C.E., 2009: Effects of cellulase and xylanase enzymes on the deconstruction of solids from pretreatment of poplar by leading technologies. Biotechnology Progress 25(2): 302-314.

14. Liu, H., Zhu, J.Y., 2010: Eliminating inhibition of enzymatic hydrolysis by lignosulfonate in unwashed sulfite-pretreated aspen using metal salts. Bioresource Technology 101(23): 9120-9127.

15. Mansfield, S.D., Mooney, C., Saddler, J.N.N., 1999: Substrate and enzyme characteristics that limit cellulose hydrolysis. Biotechnology Progress 15(5): 804-816.

16. Martin, C., Thomsen, M.H., Hauggaard-Nielsen, H., Thomsen, A.B., 2008: Wet oxidation pretreatment, enzymatic hydrolysis and simultaneous saccharification and fermentation of clover-ryegrass mixture. Bioresource Technology 99(18): 8777-8782.

17. Palmqvist, E., Hahn-Hägerdal, B., 2000a: Fermentation of lignocellulosic hydrolysates. I: Inhibition and detoxification. Bioresource Technology 74(1): 17-24.

18. Palmqvist, E., Hahn-Hägerdal, B., 2000b: Fermentation of lignocellulosic hydrolysates. II: Inhibitors and mechanisms of inhibition. Bioresource Technology 74(1): 25-33.

19. Palonen, H., Thomsen, A.B., Tenkanen, M., Schmidt, A.S., Viikari, L., 2004: Evaluation of wet oxidation pretreatment for enzymatic hydrolysis of sapwood. Applied Biochemistry and Biotechnology 117(1): 1-17.

20. PN-EN 1652, 1999: Copper and copper alloys - Plates, metal sheets, strips and discs of the general purpose.

21. PN-EN 10088-1, 2014-12: Corrosion resistant steels - Part 1: List of corrosion resistant steels.

22. Roberge, P.R., 1999: Handbook of corrosion engineering. McGraw-Hill Press. London, 309 pp. 
23. Studer, M.H., Brethauer, S., De Martini, J.D., McKenzie, H.L., Wyman, C.E., 2011: Co-hydrolysis of hydrothermal and dilute acid pretreated populus slurries to support development of a high-throughput pretreatment system. Biotechnology for Biofuels 4(1): 19-28.

24. Tomás-Pejó, E., Alvira, P., Ballesteros, M., Negro, M.J., 2011: Pretreatment technologies for lignocellulose to bioethanol conversion. Elsevier Inc., Amsterdam, Pp 149-176.

25. Warzee, M., Ruston, W.R., de Dorlodot, P., Hennaut, J., Berge, J.Ph., 1966: Corrosion of stainless in high temperature water and steam. European Atomic Energy CommunityEURATOM: 1-22.

26. Zielenkiewicz, T., Zawadzki, J., Radomski, A., 2012: XRF spectrometer calibration for copper determination in wood. X-Ray Spectrometry 41(6): 471-473.

27. Zielenkiewicz, T., Szadkowski, J., Drożdżek, M., Zielenkiewicz, A., Kłosińska, T., Antczak, A., Zawadzki, J., Gawron, J., 2016: Application of X-ray fluorescence technique for determination of heavy metals uptake by different species of poplar. Drewno 59(197): 113-126.

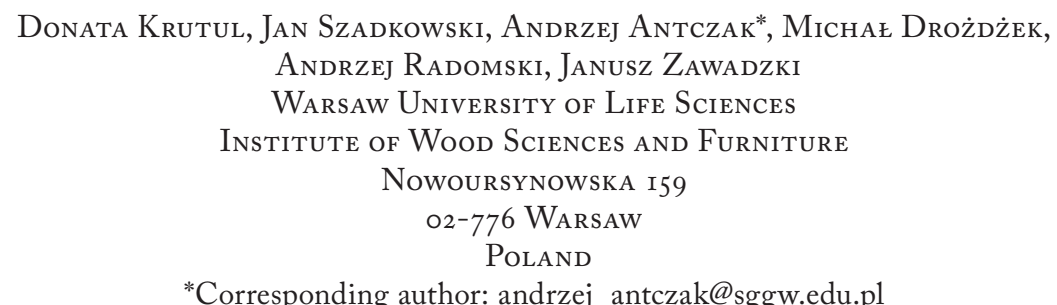

Staniseaw Karpiński

Warsaw University of Life Sciences

Institute of Biology

NowOURSYNOWSKa 159

O2-776 WARSAW

POLAND 